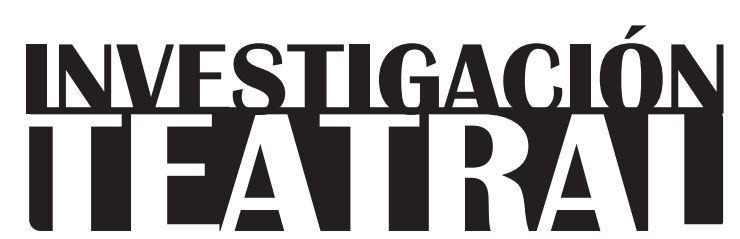

Revista de artes escénicas y performatividad

Vol. 11, Núm. 18

octubre 2020-marzo 2021

Segunda época

ISSN impreso: $1665-8728$

ISSN electrónico: 2594-0953

Afectividad, política

Universidad Veracruzana

y conocimiento:

resistencia al

neoliberalismo desde

la escena teatral

latinoamericana

Lola Proaño Gómez*

\footnotetext{
* Pasadena City College, Estados Unidos / Instituto de Investigación Gino Germani, Universidad de Buenos Aires, Argentina.

e-mail: lolaproanio@gmail.com
}

Recibido: 03 de mayo de 2020

Aceptado: 29 de agosto de 2020

Doi: https://doi.org/10.25009/it.v11i18.2654 


\title{
Afectividad, política y conocimiento: resistencia al neoliberalismo desde la escena teatral latinoamericana
}

\section{Resumen}

Este ensayo se pregunta por la forma en que se relacionan el poder y la vida en la escena teatral latinoamericana, y el peso de la afectividad en esa relación, ejemplificando las hipótesis propuestas en el análisis de Millones de segundos (Argentina 2017) y Simplemente José (Colombia 2012). El teatro es un territorio privilegiado para la expresión de la afectividad y es posible obtener conocimiento político a través de las sensaciones que los cuerpos transmiten. Siguiendo y discutiendo las propuestas del giro afectivo y con el concepto de atmósfera afectiva en mente, se propone leer las emociones que se despliegan en la escena como una forma de resistencia, desde la biopotencia al biopoder implementado por el neoliberalismo.

Palabras clave: Afectividad; neoliberalismo; biopolítica; cuerpo; teatro; Argentina; Colombia.

\section{Affectivity, Politics and Knowledge: Resisting Neoliberalism in Latin American Theatre}

\begin{abstract}
This article tries to answer the question of the articulation between power and life in the Latin American theatre scene. It reflects on the weight that affectivity has in that relationship in the field of politics, exemplified by the Latin American scene (Millions of Seconds, Argentina, 2018 and Simply José, Colombia, 2012). The theater is a privileged territory for the expression of affectivity, and it is possible to obtain political knowledge through the sensations/emotions that the characters and their bodies transmit in the scene. Discussing the affective turn theory with the help of the affective atmosphere concept, we propose to read the emotions that unfold on the scene as a form of resistance to the biopower implemented by neoliberalism.
\end{abstract}

Keywords: Affectivity; neoliberalism; biopolitics; body; theatre; Argentina; Colombia. 


\section{Afectividad, política y conocimiento: resistencia al neoliberalismo desde la escena teatral latinoamericana}

Affect is what sticks, or what sustains or preserves the connection between ideas, values, and objects.

(Sara Ahmed, "Happy Objects" 29)

$\mathrm{E}$ ste ensayo se pregunta por la forma en que se relacionan el poder y la vida en la escena teatral, así como por el peso de la afectividad en esa relación. En Millones de segundos $^{1}$ y Simplemente José, ${ }^{2}$ las dos propuestas teatrales con las que ejemplifico mis tesis, es posible observar la dinámica afectiva que, viniendo del sistema en el que la vida de sus personajes está inserta, produce emociones y reacciones políticas en tanto ellos expresan visiones y modos de vida que van directamente contra la "normalización" de la guerra en un caso y de la sexualidad en el otro. Al interpretar la relación de las reacciones emocionales de José y Alan, los dos protagonistas, a la afectación que les llega desde el exterior y relacionarlas con el conocimiento y la reflexión que tienen sobre su situación personal, adhiero a la teoría de los afectos, que no plantea una disyunción entre afectividad

1 Millones de segundos (2017), escrita y dirigida por Diego Casado Rubio y la actuación de Raquel Ameri, Estela Garelli y Víctor Labra ha sido múltiplemente premiada y reconocida. El análisis de la escena se refiere a la función que tuvo lugar en el teatro El Extranjero de Buenos Aires en la temporada de 2017.

2 Simplemente José, unipersonal de autoría, dirección y actuación de Giovany Largo León (Colombia 2012). El análisis de la obra corresponde a la función que presencié en el Festival de Formosa (2016) y los textos son cortesía del autor. 
y emoción, por un lado, y conocimiento, por otro. En las acciones de estos personajes podemos ver un pensamiento en acción que no carece de lógica ni de racionalidad: ellos ponen a la vida como el límite de la manipulación y del ejercicio del biopoder. ${ }^{3}$

El giro afectivo aporta una nueva mirada sobre el papel de los afectos en la vida pública y abre nuevas perspectivas para explorar formas alternativas de aproximarse al teatro, especialmente porque la dimensión afectiva, pasional o emocional es constitutiva de la escena que comprende, necesariamente, un tipo de razón que involucra las pasiones. Esta perspectiva permite considerar la asociación entre sufrimiento y desempoderamiento y/o victimización y discutir la vinculación de los afectos con la acción política (Michael Hardt, citado en Macón 16).

La crítica teatral puede hacer una lectura del conocimiento aportado por la escena, relevando el núcleo sensual y la emoción propias del teatro. Hernán Vidal, en una afirmación que parece adelantarse a la propuesta del giro afectivo, recomienda prestar atención a la experiencia emocional de la cotidianeidad para un mejor entendimiento del texto escénico y explorar el concepto de emoción como categoría antropológica que se refiere a las reacciones del comportamiento humano frente a circunstancias socialmente alteradas, lo que Anderson llama atmósfera afectiva. El teatro poetiza la sensibilidad social con que se experimenta la vida cotidiana y esta experiencia puede ser elevada al rango de universalidad simbólica representativa (Vidal, Crítica literaria 2-6). Esto nos puede ayudar a comprender las condiciones del contexto en que se producen las escenas, conjeturar su articulación con él y obtener conocimiento sobre las condiciones sociales y políticas de un momento dado. Para ello, tomamos los personajes teatrales como señuelos nuestros, que expresan reacciones y emociones frente a situaciones concretas de la escena, que despliega situaciones que generan una atmósfera afectiva específica; los personajes afectados responden con sus reacciones emocionales mediante el lenguaje teatral que involucra mucho más que la palabra. Ellos son índices de una visión del mundo ${ }^{4}$ que emerge como

3 El biopoder plantea la relación sistemática entre la vida y el capital, la inserción de los cuerpos en la maquinaria de producción ayudada por la tecnología para que ésta incluya el todo de la vida y el ajuste a la población (Foucault, citado en Anderson 33). El surplus/ganancia se extrae de la vida toda, nada queda afuera del mercado. Esto es lo que Negri (citado en Anderson 29) ha llamado "la real subsunción de la vida" al capital y al mercado, resultado del desarrollo de múltiples aparatos para producir y capturar valor. La vida, inserta en el proceso de producción, es el objetivo último (objective-target) y es entendida solo en términos de mercado y competencia, es el biocapitalismo (Marazzi, citado en Anderson 33).

4 Según Vidal, "La literatura -el teatro en nuestro caso- funciona con el requisito de singularizar a personajes especiales como índices del significado de una visión de mundo, jerarquizada por la reificación de un orden social ficticio" (Crítica literaria 113). 
respuesta ante la atmósfera afectiva reproducida en la escena y que, muy posiblemente, responde a situaciones socio políticas del contexto de producción.

Es posible plantear la posibilidad de detectar, en los estudios teatrales, lo político en la escena si pensamos "lo político" como un modo de acción puesto en práctica por una clase específica de sujeto -los personajes- ante la presión de un entorno específico (atmósfera afectiva/estructura del sentir). Dichas acciones se derivan de una forma particular de razón no instrumental que se exterioriza en reacciones emotivas. Explorar estas reacciones y relacionarlas con el contexto económico, político y social en el momento de la producción o con el referente espacio-temporal puede darnos un conocimiento distinto o más complejo frente al problema que la escena plantea.

Según Ruth Leys, el afecto es una experiencia no consciente de intensidad; es un momento de potencial sin forma ni estructura, que tiene siempre prioridad y externalidad respecto de la conciencia y por ello, no puede ser concretado totalmente en lenguaje. Es también el modo del cuerpo de prepararse para la acción en una determinada circunstancia añadiendo una dimensión cuantitativa de intensidad a la cualidad de la experiencia ("The Turn" 442). Foucault, a su vez, afirma que el afecto (al que denomina object-target) se acciona en la intersección de las relaciones de conocimiento y las relaciones de poder que emerge de "aparatos" específicos. Un "aparato" es, según Foucault, un sistema de relaciones que surge entre elementos discursivos y no discursivos heterogéneos, que tiene como función estratégica responder a una necesidad urgente y consiste en "una cierta manipulación de las relaciones de fuerzas, ya sea desarrollándolas en una dirección particular, bloqueándolas, estabilizándolas, utilizándolas, etc." (1980, 196). En este sentido, podemos considerar el teatro como un "aparato" atrapado en las relaciones de poder, el cual contiene elementos discursivos y no discursivos que, estratégicamente, responden a necesidades planeadas en la escena consciente o inconscientemente, que aparecen como urgentes y que responden a la atmósfera afectiva. El teatro así entendido sería un "aparato" que tiene la potencialidad de desestabilizar o denunciar un cierto estado de cosas haciendo que sus personajes se desenvuelvan y reaccionen emotivamente frente a una atmósfera afectiva específica producida por las relaciones de poder, los intereses y la ideología del statu quo. En este marco conceptual, el teatro resulta un objeto privilegiado, puesto que pone en juego la capacidad política de los afectos que, en la escena, tensionan la relación entre el poder, el conocimiento y la resistencia que presentan los personajes.

El teatro se convierte en un objeto aventajado para brindar conocimiento del contexto histórico-político que revelan los afectos, en tanto ningún producto cultural expresa la capacidad performativa de los mismos como la escena teatral; en ella, mediante la multiplicidad de lenguajes, se supera la performatividad exclusiva del lenguaje verbal (Austin) y se responde al hecho de que al cuerpo y a sus modos de expresión le resulta insuficiente la expresión exclusivamente verbo-lingüística. La escena construye con los afectos una lógica 
INVESTIGACIÓNTEATRAL

Revista de artes escénicas y performatividad

Vol. 11, Núm. 18

octubre 2020-marzo 2021
Afectividad, política y conocimiento

Lola Proaño Gómez

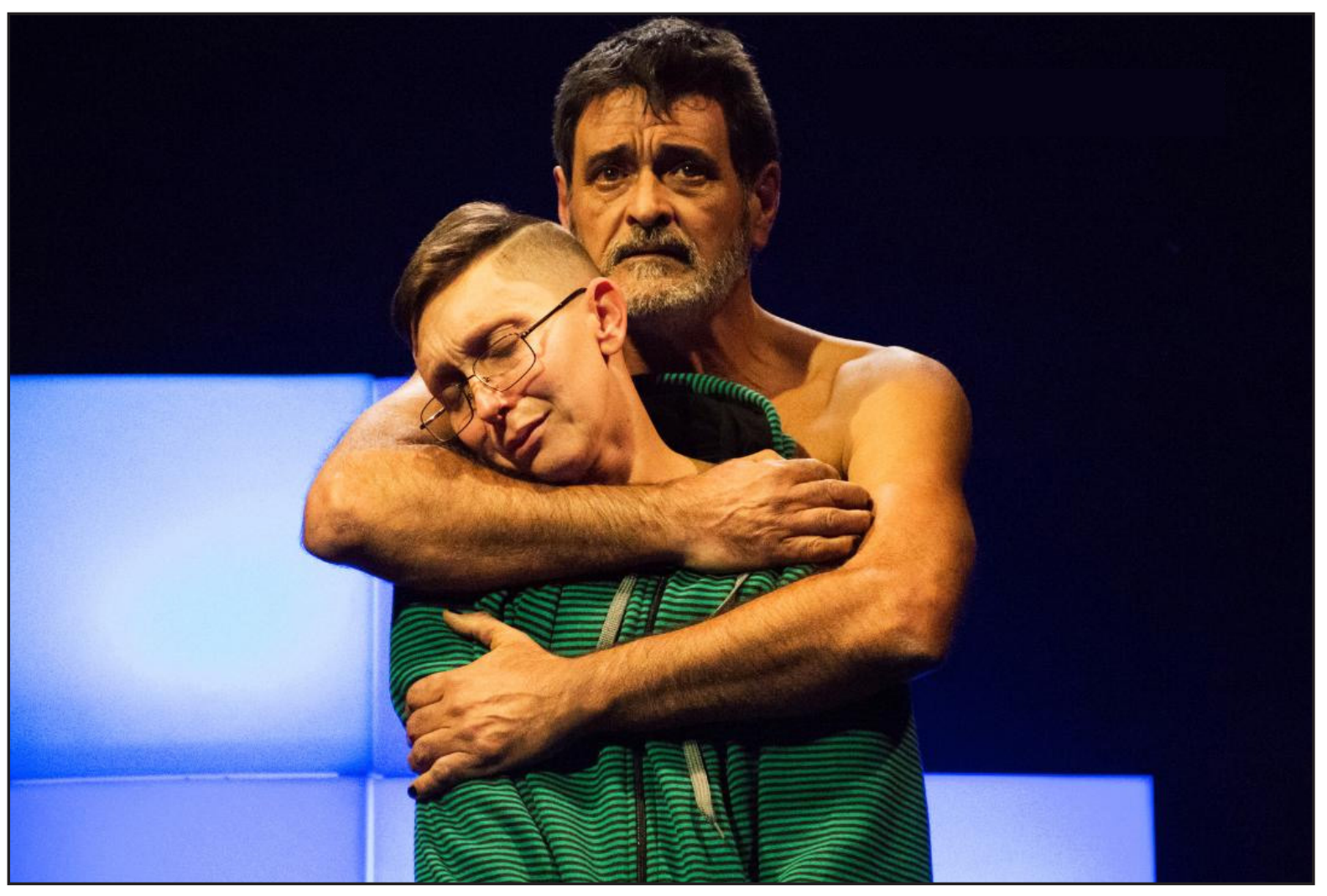

Sansón (Víctor Labra) y Alan (Raquel Ameri) en Millones de segundos. Teatro El Extranjero, Buenos Aires, Argentina, 4 de junio de 2017. Fotografía de Leila Sucari.

capaz de visibilizar los lazos sociales y las luchas políticas que se revelan como impulsos para la acción política. Esta lógica rebasa la mera instrumentalidad, pues son parte constitutiva de ella las emociones, los deseos, los recuerdos y la memoria, aspectos que juegan un papel fundamental y que dan forma a una lógica que contiene todos estos elementos considerados "no racionales" en términos de la lógica instrumental.

Por todo lo dicho, considero importante y fructífero integrar lo afectivo al estudio del teatro, en tanto que permite discernir de modo más complejo y en conjunción con aspectos literarios, visuales y epistemológicos la política ínsita en toda propuesta teatral. En Simplemente José y Millones de segundos, propuestas de las que hablaremos en detalle más adelante, los personajes están inmersos en dos atmósferas afectivas violentas que son el germen del orden emocional de la escena. Las "emociones negativas" aparecen especialmente en Millones de segundos donde predominan la ansiedad, la frustración y la rabia que son, en este caso, fuentes de resistencia. 
Es importante tomar en cuenta el origen histórico de los sentimientos negativos, que muchas veces son respuestas a la injusticia social o a otras situaciones políticas frente a las cuales los personajes luchan contra la sensación de impotencia: José, en Simplemente José, resiste mediante el recurso a la memoria y a la imaginación poética, y Alan, en Millones de segundos, intenta superar su situación, aunque no tenga éxito en ello. Por otra parte, es necesario historizar dichas violencias, ellas son distintas y nos obligan a remarcar la importancia de articular las emociones desplegadas en la escena teatral, con el contexto y los hechos históricos y políticos. En Simplemente José la nostalgia no obtura el presente ni el futuro, ni tiene el aspecto conservador de querer restaurar el pasado. ${ }^{5}$ Todo lo contrario, esa nostalgia enjuicia la guerra colombiana, la cuestiona y descubre sus consecuencias. ${ }^{6}$

Simplemente José es la búsqueda poética y emotiva de respuestas mediante el autoconocimiento. El trayecto del personaje puede resumirse como el camino, con un destino desconocido, al que se llega mediante la conservación de la memoria y la búsqueda del sentido de la vida, no afuera del sujeto sino en la introspección, tal como el personaje confiesa: "viajar de adentro a afuera y conocerse para no vivir engañado, ser quien realmente somos". Por otra parte, Diego Casado Rubio afirma, respecto de Millones de segundos, que "mucha gente [alcanzó conocimiento, pues le] dice que gracias a [su] obra derribaron sus prejuicios acerca de la transexualidad, que aprendieron a tomar conciencia de la diferencia y de que el cuerpo es tan sólo un envase que no tiene por qué identificarnos".

\section{Estructura de sentimiento, atmósfera afectiva y producción de conocimiento}

He sostenido, en investigaciones anteriores, que la escena teatral es el espacio de la expresión de la estructura del sentimiento ${ }^{7}$ entendida como "una conciencia práctica que se

5 El pasado simple, puro, ordenado, fácil, hermoso o armónico es construido (y luego experimentado emocionalmente) en conjunción con el presente que, a su vez, es construido como complicado, contaminado, anárquico, difícil, feo y confrontacional. Siempre tiene las dos dimensiones; evocación de un mejor pasado y descontento ante el presente hostil (Hutcheon, citado en Solana, "El tiempo" 237). El recuerdo del pasado de José no está libre de las amarguras que se vivieron.

6 El origen de la palabra: en 1688, el médico suizo Johannes Hoffer combinó los términos griegos nóstos -vuelta a la patria, regreso- y álgos -dolor, pena- para acuñar el término nostalgia y describir el dolor experimentado en aquellos que sueñan volver al hogar. Pero el regreso al espacio es posible mientras que el regreso al tiempo es imposible, esto es lo irreversible que da lugar a la nostalgia (ibídem).

7 Ver Proaño, Poética, política y ruptura. 
manifiesta en tensión entre la cultura dominante y la que quiere emerger, se manifiesta en las contradicciones de la experiencia vivida cuya expresión se encuentra en el "borde de la eficacia semántica" (Williams, "Estructura" 157). ${ }^{8}$ Creo que la escena teatral articula esta estructura que, formada por un grupo de relaciones específicas entrelazadas y en tensión, es una experiencia social en proceso que, en el análisis, tiene sus características emergentes, conectoras dominantes y presenta jerarquías específicas (153-157). Ben Anderson reelabora la "estructura del sentir" propuesta por Williams y, siguiendo a Virno (2004), propone la existencia de una "atmósfera afectiva", que ostenta una semblanza familiar con el concepto de Williams ${ }^{9}$ puesto que implica, en sentido duplicado y contradictorio, lo efímero y lo transitorio junto a lo estructurado y duradero: un fenómeno colectivo compartido.

En este trabajo llamaré afectos a los procesos de interacción social que se dan y se reciben, se trasladan y forman la atmósfera afectiva. Las emociones, a diferencia del afecto, se producen dentro del organismo y son una respuesta individual interna a dicha atmósfera. Es decir que el afecto es el resultado de una interacción social, y la emoción, la respuesta individual a la atmósfera afectiva producida por esos afectos. En la escena teatral las emociones están en el obrar y las reacciones de los personajes frente a la afectación que viene de la interacción social y que en la escena alude al contexto político y social.

Frente a la atmósfera afectiva, análogamente producida en la escena, las emociones de los personajes teatrales surgen en la tensión entre la cultura dominante y la resistencia a ella y en las contradicciones de la experiencia vivida por cada uno de ellos. La atención en el elemento afectivo y las reacciones emocionales posibilitan un mejor entendimiento del sometimiento o la resistencia al orden social que presentan los personajes, y permiten detectar el surgimiento de nuevos órdenes sociales que desafían la normatividad en la escena teatral.

8 La estructura del sentir se forma por experiencias sociales en soluciones que no son evidentes. El teatro como los otros productos culturales son formas de articulación de las estructuras del sentir: procesos vivientes experimentados más ampliamente. La estructura del sentir se relaciona como solución con las formaciones emergentes y son formaciones estructuradas, articulaciones específicas que se descubren en la práctica material; eslabonamientos particulares, acentuamientos y supresiones, puntos de partida y conclusiones. El teatro, en tanto articulador de la estructura del sentir, incluye elementos de experiencia social o material (Williams, "Estructura" 157).

$9 \quad$ Flatley describe el mood como una "suerte de atmósfera afectiva que atraviesa a los sujetos, un estado inevitablemente compartido, un fenómeno colectivo. En este sentido 'los modos constituyen el modo en el que estamos juntos" (Abramowski, "La vocación" 81). 
En la escena teatral es posible observar cómo las atmósferas afectivas se toman y se trabajan en la vida y cómo nuestros personajes lidian en sus respectivas situaciones haciendo de sus emociones, en algunos casos, elementos de resistencia. Este "cómo" implica siempre una posición ideológica y un conocimiento histórico y político que guía las acciones intencionalmente (Anderson 8).

Lo afectivo en los estudios teatrales puede producir una "comprensión diferencial de experiencia subjetiva y de procesos sociales" (Abramowski, Pensar 17) que se manifiestan en una emotividad (mood) que responde a la atmósfera afectiva que también puede expresarse en el teatro en forma de imaginarios alternativos, deseos, pasiones, utopías, frustraciones, que tienen la característica de ser compartidos como un fenómeno colectivo (Flatley, citado en Abramowski, "La vocación" 80). En este sentido, la propuesta del giro afectivo podría constituir una hermenéutica para el análisis del teatro, pues amplía la comprensión tanto de las motivaciones y/o intencionalidad de los productores y de las fuerzas que mueven a los personajes en la escena como de las interacciones sociales que, al momento de la producción, producen una atmósfera afectiva específica que parece responder al contexto y que reaparece en la escena teatral. Así, las reacciones y acciones de los personajes se pueden entender como emergentes de la sensibilidad social compartida.

El teatro tiene la corporalidad como su núcleo fundamental, está hecho de los cuerpos de los actores y, por ello, es el ámbito privilegiado para la expresión de la afectividad. De acuerdo a Spinoza, "cuanto más próspera es la experiencia corporal, más compleja y clara es la experiencia del alma-mente" (citado en Lossigio 50). La interacción corporalidad-conocimiento se produce en el ámbito afectivo, propio de la escena; ésta enriquece el conocimiento, pues a través del cuerpo y de las sensaciones que esos cuerpos nos transmiten es posible obtener un conocimiento más complejo y no sólo dirigido al razonamiento intelectual que, en general, sólo aparece luego de la experiencia. En este sentido, el espectador recibe el impacto de la afectividad desplegada en la escena, se ve afectado por ella y responde, como los personajes, desde sus emociones y su conocimiento, con aceptación o rechazo del planteamiento escénico. Se trata, entonces, de que en la sala teatral también se genere una atmósfera afectiva frente a la cual los espectadores reaccionen emotivamente. A esto responde la necesidad de compartir la escena teatral, necesidad que se concreta en las discusiones que se dan a la salida de la sala o en las críticas escritas a posteriori. Los dos casos son respuestas ante la afectación recibida desde la escena; reaccionamos a ella, desde nuestras emociones y nuestra razón, nuestro conocimiento y nuestra posición político-ideológica, con aprobación o con rechazo.

Consideremos, además, lo que propongo llamar sinestesia teatral, entendida como la combinación de los múltiples lenguajes teatrales, así como su diverso y entrecruzado 
impacto en los sentidos; estos hacen estallar la posibilidad de una comprensión afectiva ampliada, no circunscrita a la lógica proposicional: la luz nos da tristeza o alegría, los sonidos disparan recuerdos, la visión de los movimientos transmite ansiedad o tranquilidad, por ejemplo. Esta comprensión afectiva desentraña sentidos que están mucho más allá del lenguaje verbal, visual (la pintura) o sonoro (la música), pues el teatro combina todos estos lenguajes causando un impacto sensorial múltiple y con ello una comprensión más compleja de la realidad política expresada en la escena. Esta es la ventaja de la escena teatral respecto de otras expresiones culturales.

Ruth Leys plantea el problema en el que caen muchos teóricos del afecto en humanidades y ciencias sociales, quienes adoptan la separación del afecto de nuestras ideas y creencias al tratarlos como estados no intencionales, como reacciones automatizadas del cuerpo frente a ciertas causas externas; esta posición anti-intencionalista de los afectos se debe a la fuerte influencia de la neurociencia. Una de las razones esgrimidas para separar lo afectivo del conocimiento es que se identifica el conocimiento exclusivamente con la habilidad de hacer proposiciones lingüísticas -característica que define a lo humano- que deben expresarse en términos "científicos". Esto, que es remanente de un mal entendido positivismo, basa toda adquisición del conocimiento en el lenguaje proposicional y pretende dejar la ideología fuera del lenguaje. Adhiero con Leys la posición cognitivista, sobre todo si hablamos de teatro y su relación con la política y la ideología; el escenario teatral rebasa, como ya hemos dicho, el límite de la expresión lingüística y por ello no puede ser leído en términos pseudo positivistas exigiéndole que toda idea sea expresada en un lenguaje "científico". ${ }^{10}$

Por otra parte, no sólo los afectos positivos son formas críticas de producir nuevos conocimientos y estimular la acción política. Según Flatley (citado en Macón y Solana 17-35), por ejemplo, las melancolías no depresivas no obstaculizan nuestro interés por los otros, sino que habilitan de modo particular la conexión vital con el exterior, tal como ocurre en los dos escenarios teatrales que nos sirven de ilustración en este ensayo. El personaje de Simplemente José, por ejemplo, provee conocimiento del mundo de la guerra colombiana mediante la melancolización de la memoria: aún la inercia y la desespera-

10 Leys afirma que la situación actual ofrece al historiador y al crítico el creciente fenómeno de un clash que está ocurriendo entre modos diversos de entender las emociones. Una dificultad para defender el paradigma intencional de los afectos es que uno se ve obligado a proveer descripciones de experiencias de vida de la clase que es familiar a los antropólogos y los novelistas, pero que es hostil a la ciencia. La discusión no interesa en este caso, pues adoptamos sin problema la versión intencionalista puesto que no afirmamos la irrelevancia del significado o la disputa ideológica para el análisis cultural, sino, justamente, lo contrario. 
ción pueden servir para forjar comunidades y proyectos en común, tal como sucede en otros casos (por ejemplo, en el teatro comunitario). ${ }^{11}$

Como resultado de lo dicho en la escena teatral, podemos preguntarnos: ¿Cuál es la situación ante la cual los personajes exhiben sus sentimientos? ¿Cuál es la relación de estos con la política, la memoria y la historia? ¿Los personajes con sus acciones, son cómplices o resisten una situación concreta de la escena y su contexto? ¿Cómo se transmite esta atmósfera afectiva? ¿De qué herramientas hace uso el teatro para transmitirla? ¿Hasta qué punto los personajes, sus afectos y la situación desplegada en la escena responde al contexto político-social en el que surge la propuesta teatral? Para responderlas, reflexionaré sobre las dos propuestas teatrales ya mencionadas, sirviéndome del giro afectivo y su capacidad hermenéutica de transmitir conocimiento respecto de la dimensión política de la escena y su contexto.

\section{Marginalidad, atmósfera afectiva y emociones}

Los personajes dramáticos son índices de una visión del mundo que se opone a la visión del mundo hegemónica en la medida en que resisten la reificación del statu quo.

(Hernán Vidal, Crítica literaria 45)

Las dos propuestas teatrales señaladas son muy diversas tanto en su tema como en su teatralidad, aunque ambas consideran dos formas de marginalidad que se dan en nuestro presente: Simplemente José expone la marginación y el dolor de la guerra colombiana, que ya lleva más de cincuenta años, con énfasis en el desplazamiento campesino; Millones de segundos escenifica la incomprensión y limitaciones sociales impuestas a los sujetos transexuales y expone la "expansión de la normalización" para obstaculizar el acceso del personaje transexual a un derecho reconocido legalmente. Dos formas de marginación diferentes, dos puntos geográficos distantes y dos teatralidades diversas.

Estos dos productos teatrales vistos bajo el lente de la afectividad pueden facilitar la comprensión diferencial surgida de compartir co-afectivamente -la escena y los espectadores - los problemas de la cotidianeidad y las vivencias personales de deseos, esperanzas y frustraciones que se plantean en los dos escenarios. En ellos veremos cómo los personajes

11 Tal como he tratado extensamente en Teatro y estética comunitaria. Miradas desde la filosofía y la política. 
lidian con sus situaciones mediante una performatividad afectiva expresada poética y nostálgicamente en Simplemente José y mediante la desconformidad manifestada en la rabia, la ansiedad y la frustración en el caso de Millones de segundos.

Si consideramos que el escenario teatral es el espacio de expresión de la estructura del sentimiento/atmósfera afectiva existente en el momento de su producción, es posible plantear que estas dos propuestas, si bien son ficticias, revelan posiciones, pensamientos y ubicaciones políticas en el panorama contemporáneo del contexto de producción, en este caso Colombia y Argentina. Tanto Simplemente José como Millones de segundos son claros ejemplos de la "inmediatez generativa" (Williams, "Estructura"), procedente de formaciones sociales emergentes y que están conectadas con afectos específicos estrechamente conectados a lo social y a las diferencias políticas del contexto en el que surgen. La existencia de la guerra colombiana, las leyes y los juicios que descriminalizan las sexualidades alternativas, junto con la resistencia a obedecerlas en Argentina, son la condición de posibilidad de los dos escenarios teatrales.

La vida de José y Alan, los dos protagonistas, está sujeta a las técnicas del biopoder cuyo imperativo es proteger el modo de vida y de existencia convenientes para el mantenimiento del capitalismo neoliberal, ${ }^{12}$ al mismo tiempo que desecha y abandona las "otras vidas" para conservar aquellas consideradas valiosas dentro del modelo cultural hegemónico. En la propuesta colombiana, la marginación del personaje es consecuencia del poder que defiende el capital y el mercado. Éste necesita sujetos que respondan a la subjetividad delineada por el neoliberalismo conformada por la presencia de deseos insaciables que producen lujuria, orgullo y avaricia, intereses desinteresados selectos como son la caridad y la compasión y, finalmente, un sujeto en el que prima el interés propio (self interest) utilitario. En suma, el sujeto neoliberal es el apropiado para el mundo en el que la competencia (fundamentalmente económica) es el valor y la medida trascendente y el dinero el valor más jerarquizado. Todo esto, intensificado por la privatización, la personalización, la exaltación del individuo y la responsabilización por la vida y la muerte de las que el Estado se ha retirado.

12 Este estado "normal" de existencia está muy bien explicitado por Vidal: "la cotidianidad se presenta a la conciencia del individuo ya socialmente disciplinado para cumplir los roles, funciones y rutinas que le corresponden esencialmente como un conjunto de actividades ya estabilizadas, que abarcan, espacios y temporalidades bien demarcadas (hogar, familia, barrio, amigos, escuela, club, parques, calles, lugares de trabajo) y convertidas por su frecuencia en hitos 'naturales' de facticidad rotunda e inapelable que parecen desarrollarse automáticamente, a las cuales el individuo pareciera poder reintegrarse espontáneamente, sin un alto grado de readecuación de su energía corporal y psíquica" (Crítica literaria 4). 
En el caso argentino, la marginación de Alan es consecuencia de la expansión de la normalización para conseguir una homeostasis social, afincada en tradiciones fuertemente conservadoras que se oponen a la apertura legal sancionada que reconoce el derecho a la elección de identidad de género. El capitalismo necesita la estructura familiar con los roles de género bien definidos para proveer sujetos útiles al sistema que necesita de su trabajo para reproducir la ganancia. Los sujetos como Alan, que rechazan la conformación genérica y familiar tradicional, son un peligro para el sistema.

Tanto el espectáculo colombiano como el argentino despliegan personajes que están en el espacio opuesto a la subjetividad ideal del modelo capitalista neoliberal. En ellos predomina el deseo de alcanzar una vida plena; su meta no tiene nada que ver ni con la ganancia ni con el mercado.

José persigue la sobrevivencia mediante la conservación de la memoria; reflexiona sobre la guerra colombiana, el desplazamiento, la muerte y el amor; su trayectoria marca la búsqueda de la identidad y de respuestas esenciales. Un ejemplo del rechazo de José a los valores neoliberales es su parodia de la caridad -el interés desinteresado propio del capitalismo- como una institución inútil, hipócrita y ridícula. Esto ocurre en la escena, cuando la "doctora" una "gordita muy chistosa" lo rescata y lo incluye en el programa de "desplazados" de la primera dama; en la escena, José denuncia la ignorancia y la falsedad de este interés desinteresado que oculta desconocimiento y desprecio. Ella lo saluda: "hola miamor, cómo está mi rey" y le pide que ponga una cruz y la huella en el lugar de la firma, asumiendo su analfabetismo. José pone la huella y la cruz y luego firma su nombre; sin palabras, ha descubierto la presunción de ignorancia y la pretensión de ayuda caritativa frente a ella. Del mismo modo, Alan en Millones de segundos, explícitamente denuncia como negativos el valor trascendente de la competencia y la avaricia, componentes esenciales de la subjetividad neoliberal: "en este mundo lo único que de verdad muere, lo único que de verdad se castiga... es que te saquen la plata. Lo demás no importa". Se siente preso de ese sistema, pues ha "nacido con el cuerpo equivocado"; por eso, se siente "secuestrado" e "invisible" dentro de un sistema que se niega a reconocerlo. La resistencia de la institucionalidad -la escuela, la familia (presente en el personaje de la Madre), la medicina, la justicia- se debe a que su cuerpo no le sirve al neoliberalismo que necesita cuerpos reproductores, "mujeres verdaderas".

La emocionalidad que se despliega en el escenario no es homogénea, en ella existe una multiplicidad de afectos y expresiones. Al mismo tiempo que la escena expone la existencia de una pluralidad de "comunidades emocionales", ${ }^{13}$ en una actitud abierta-

13 Estas comunidades emocionales son socialmente producidas, cohesivas y están basadas en emociones comunes; además, tienen propias y diferentes normas de evaluación y expresión que condicen con resistencias o insistencias. 
INVESTIGACIÓNTEATRAL

Revista de artes escénicas y performatividad

Vol. 11, Núm. 18

octubre 2020-marzo 2021

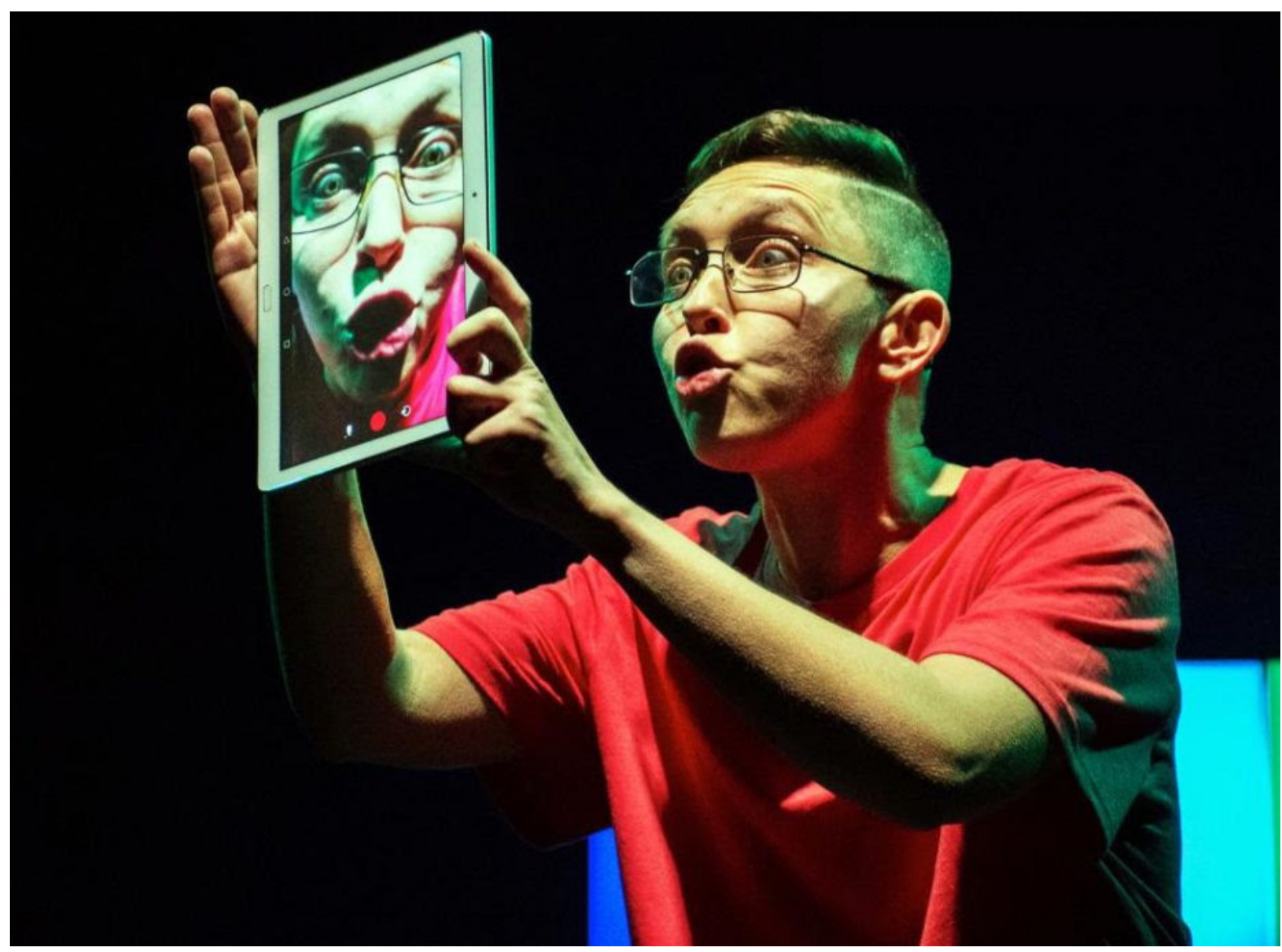

Raquel Ameri como Alan en Millones de segundos. Teatro El Extranjero, Buenos Aires, Argentina, 4 de junio de 2017. Fotografía de Leila Sucari.

mente política toma partido por la biopotencia que resiste desde la vida y deslegitima la guerra y la discriminación. Millones de segundos exhibe las "razones" creadas ad hoc para evitar la concretización de la ley a favor del cambio de género, mientras que Simplemente José cuestiona la guerra, el progreso, la intelectualidad y pone en duda la ignorancia del campesino. Desde la perspectiva marginal y mediante la teatralización de los afectos, estas dos propuestas resisten el statu quo y dan lugar a la expresión de deseo de los cambios sociales y políticos.

Observaremos entonces cómo estos nuevos modos de imaginar o recrear vida fuera del paradigma del sujeto neoliberal son teatralizados con estas dramaturgias enraizadas en experiencias tomadas de la realidad respondiendo, en el proceso de producción, a lo que llamamos "inmediatez generativa". Las dos propuestas aprovechan el vínculo entre 
afecto, política y contingencia. Simplemente José busca cuestionar y preguntarse por la posibilidad de un modo de vida alternativo en el espacio de la imaginación; ${ }^{14}$ Millones de segundos exhibe y denuncia la resistencia mediante la rabia y la rebeldía ante la imposibilidad de alcanzar que se haga efectivo el reconocimiento al derecho de identidad de género, el derecho a cambiar su cuerpo.

\section{Memoria, testimonio y afectividad}

...es posible pensar el modo en que los artistas exploran las formas de lo politico a partir de cómo plasman emociones, sentimientos y afectos 'no como un medio de escape narcisista sino como una forma de compromiso social.'

(Doyle XI, citado en Taccetta, "Arte, afectos y política" 287)

[El teatro]...es una herramienta eficaz para hablar de lo que somos, de lo que nos queremos convertir como sociedad y para alivianar las cargas los temores y fortalecer la esperanza.

(Largo León, entrevista)

Nos preguntamos por el carácter testimonial de estas dos obras que parten de sucesos reales inscritos en la memoria, pero de los cuales ni los autores ni los personajes de la ficción son testigos directos; ellos hablan por delegación y como consecuencia de conocer hechos

14 Si bien es cierto que se ha enfatizado el efecto negativo de la tecnología mediante la manipulación de los afectos, éste no es el caso en Millones de segundos: Alan, el/la protagonista resiste con la ayuda de su tablet y de su cuerpo. En lugar de que la tecnología manipule su capacidad afectiva de manera inconsciente, nuestro personaje la convierte en el arma que le posibilita salir al mundo sin dejar su encierro; no hay decisiones pre-conscientes ni desde el sistema. Alan se comunica con el mundo prescindiendo de su cuerpo -del que quiere deshacerse o modificarlo-. ¿Es esto una resistencia o una capitulación? ¿Es la búsqueda de la comunicación sin involucrar la biología rechazada? La tecnología en este caso no es una extensión de la biopolítica, pues no persigue disciplinar el cuerpo; no es un medio eficiente de control ni induce la toma de decisiones. Millones de segundos parece afirmar que la tecnología no es necesariamente el mal y que esa calificación depende del uso que se haga de ella. Por otra parte, José, debido a su situación de campesino desplazado, no tiene ningún acceso a la tecnología y a través de su discurso podemos ver que cree más en el conocimiento alcanzado por la autoreflexión que a través de los avances tecnológicos. 
que los han impactado afectivamente. Según Agamben, el testimonio es la intimidad traumática que surge del contacto personal con una realidad inhumana (34). Parece entonces que esta intimidad traumática no necesita ser sufrida ni padecida directamente por el testigo. Su testimonio puede deberse al contacto personal con una realidad inhumana, aunque ello no corresponda a una vivencia directa y personal.

Resulta interesante tomar el concepto de posmemoria propuesto por Hirsch: esta es distinta de la memoria a causa de la distancia generacional que "sobredetermina la conexión personal con el pasado" (114). Si bien en los dos casos objeto de este ensayo no hay distancia generacional, pues las dos narraciones corresponden al presente de sus productores, ellas no pertenecen a su propia experiencia de vida. Son "memorias" reconstruidas desde documentos o narraciones de los sujetos que vivieron los acontecimientos. Nos preguntamos, entonces, ¿qué tipo de memoria se escenifica y qué tipo de testimonio dan estas dos propuestas? ¿Cómo se pueden considerar testimonios si narran acontecimientos que sucedieron a terceros?

En este sentido, creo posible extender la propuesta de Hirsch y afirmar que junto a la posmemoria aparece el testimonio afectivo (Taccetta, "Arte, afectos y política" 303). Hay una distancia experiencial que marca la conexión e interpretación del pasado reciente: el testigo lo es sólo en calidad de delegado que realiza una reconstrucción del testimonio. El productor (dramaturgo y actores/actrices) conoce los acontecimientos de modo diferido, se vincula con ese pasado de modo afectivo y se sumerge en una realidad que le sobrepasa y que desea denunciar. La escena en este caso no tiene valor indexical, sino más bien evocativo en el que interviene la activación procedente de la vida política (302).

La distancia entre el acontecimiento narrado y el proceso de creación de la escena se sortea mediante el puente afectivo experiencial y temporal que produce una nueva memoria visual y emotiva. En los dos casos objeto de este ensayo, los productores han tomado contacto con estas historias mediante lo que parece haber sido una identificación casi visceral que convierte la historia narrada en un instrumento quasi testimonial, cargado de sensibilidad. Este postestimonio afectivo se presenta con la potencia agregada de los lenguajes teatrales que fortalecen y amplían la relación entre la escena y los espectadores, que vibran intensamente impactados por la combinación de los lenguajes escénicos, lo que he llamado sinestesia teatral.

Detengámonos en el proceso de producción de los dos espectáculos que ejemplifican el funcionamiento escénico de la posmemoria y el testimonio afectivo. Simplemente José plasma en el escenario el desplazamiento de campesinos causado por la guerra colombiana. Su autor, Giovanny Largo León, nos cuenta cómo surge su propuesta dramatúrgica y la escena. 
INVESTIGACIÓNTEATRAL

Revista de artes escénicas y performatividad

Vol. 11, Núm. 18

octubre 2020-marzo 2021

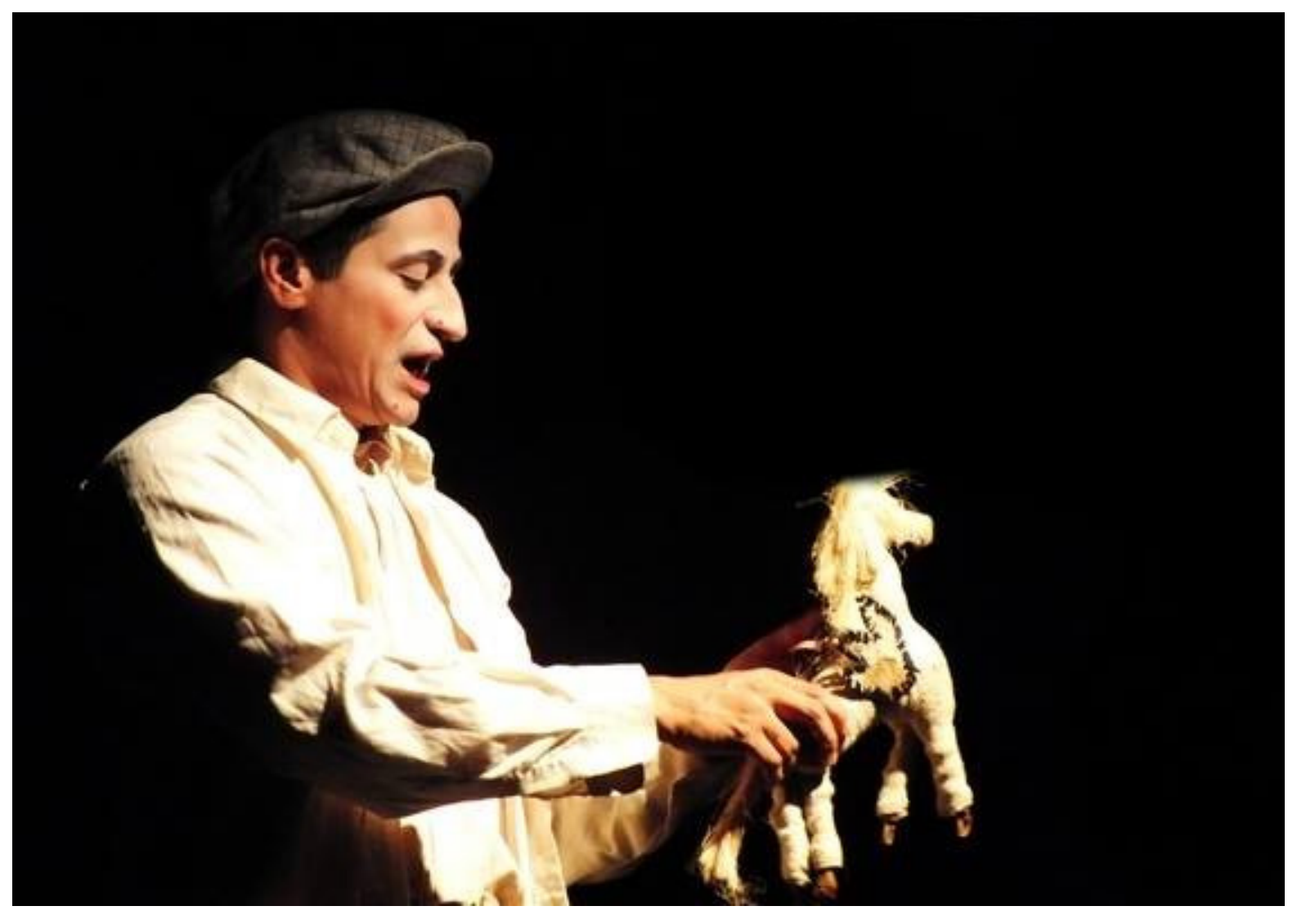

Simplemente José. x2 Teatro, Manizales, Colombia. vir Muestra de Teatro Alternativo de Pereira, 27 de julio de 2015. Fotografía de Andrés Felipe Rivera.

Él trabajaba en la Secretaría de Cultura de Caldas y parte de su trabajo era viajar a la zona rural donde llegaba a los pueblos, siempre previo aviso por la situación de peligro que se vivía. Esto le permitió "conocer de primera mano la situación que vivían los desplazados, las víctimas de la lucha armada en Colombia". Empieza entonces a realizar un proceso de investigación: recopila notas de prensa, récords de la policía y, sobre todo, le da protagonismo a la oralidad de la historia contada por los campesinos. En la narración del proceso -la parte no-representacional del proceso de creación-podemos visualizar cómo se genera el punto de inflexión entre la afectación que viene de la guerra colombiana y la reacción de Largo León plasmada en la escritura del texto y la creación de su personaje; observaremos cómo, en el proceso, los afectos tienen protagonismo central en el tendido del puente afectivo espacio-temporal que produce una nueva memoria visual y emotiva. Largo León dice: 
En mi interior suceden muchísimas cosas, hay una confrontación muy grande con los hechos que voy descubriendo, una confrontación con la realidad, hasta donde supera la ficción y hasta donde empiezo a formularme preguntas sobre nuestros miedos, nuestra perversidad, el deseo de poder, todo lo que tiene que ver con el fenómeno de la guerra (Entrevista).

Esto explicita el punto de inflexión entre reaccionar ante la guerra con odio, desesperanza y todo tipo de sentimientos negativos ${ }^{15}$ que nuestro personaje supera para crear algo que nace desde el deseo y la defensa de la vida. En el caso de Diego Casado Rubio, sucede algo que tiene puntos de contacto con lo que acabamos de plantear; también Millones de segundos se origina en un hecho de la realidad, pero que tampoco fue una experiencia vivida por su autor. El programa de mano describe así la propuesta:

Cuando tenía cinco años -explica el programa- Alan supo que era de otro planeta y empezó a contar los segundos que le quedaban para dejar de vivir en un cuerpo equivocado. Hoy tiene 554 millones de segundos y aún conserva la esperanza de empezar su transformación y poder seguir usando el baño de varones. La historia sucedió y es el origen de este conmovedor suceso escénico. Hoy Alan sigue contando los segundos para salir de ese cuerpo que siente como ajeno, sin perder la esperanza de la transformación quirúrgica de su cuerpo que le es negada, debido a que Alan sufre el síndrome de Asperger.

Según Casado Rubio, la idea apareció después de ver un video en YouTube donde se veía a un chico, en una habitación de su casa, autogolpeándose y a su perro tratando de evitarlo. El video terminaba con un abrazo hermoso entre ambos, el perro totalmente entregado a la protección del chico que lloraba de angustia por la crisis nerviosa que acababa de sufrir. Ante esto, Casado Rubio, al igual que había hecho Largo León, se pone a investigar sobre el chico del video y sus circunstancias. Descubre, entonces, que la crisis se debía al síndrome de Asperger y que el chico era transexual: había nacido en cuerpo de mujer, pero se autopercibía hombre. Casado Rubio dice haberse documentado, investigado, charlado, informado, recopilado documentales y videos en YouTube de chicos y chicas trans y documentales sobre el autismo. Ante esto, le surge la necesidad de contar esta historia que habla del gran conflicto de Alan, entre su deseo que busca la

15 Losiggio cita a Sianne Ngai en Ugly Feelings cuando afirma que una inacción o un temple "inerte" puede ser considerado también un tipo de acción política. La pasividad puede también implicar resistencia y un modo de rebelarse contra el sistema (51). 
reasignación de sexo y la prohibición médica de llevarlo a cabo esgrimiendo el autismo como la justificación médica para negarle ese derecho (Casado Rubio, entrevista). Diego se confiesa un contador de historias y revela cómo la afectividad es un factor importante en el origen de su hacer teatral: "las historias que elijo contar son las que me emocionan, me conmueven, me generan la visceralidad del grito, de la denuncia, de la risa y del entretenimiento... Me gusta la sorpresa, lo inesperado, la cachetada, lo poético, la mezcla de géneros y estilos". ${ }^{16} \mathrm{El}$ aspecto emocional está ya en germinación de la obra y es también, en este caso, el puente afectivo que produce el traspaso de la memoria a través del tiempo y el espacio. Las afirmaciones de Casado Rubio en la entrevista confirman la relación entre la emoción como expresión del afecto, el conocimiento valorativo y la necesidad de expresarlo en la escena.

En el caso colombiano, el espectador se acerca a la experiencia de los desplazados de la guerra colombiana desde la dialéctica emotiva pendular que oscila entre la melancolía y el humor. Una vez ubicados en el nivel de la imaginación de José, las imágenes nos re-envían a otras imágenes para ir tejiendo los sentidos y el rechazo a la situación de la guerra colombiana y nos conecta con sus sucesos mediante sensaciones de una memoria que no es nuestra. Valiéndose de la potencia polisémica de las imágenes y acercándose a la poesía, José juega con la ausencia de los muertos y desplazados, además de que genera el deseo de su presencia intentando captar ese mundo desaparecido. Este movimiento pendular entre pasado y presente, hechos e imaginación, poesía y realidad, nos abre la entrada a un relato que sigue una lógica afectiva: los afectos funcionan como "un vaso comunicante" a través del cual la historia se abre paso en la estética (Jonathan Flatley, citado en Depetris Chauven 119).

El impacto de aquello que no se expresa totalmente, pero que se siente a nivel afectivo y emotivo, tiene la potencia para generar un nuevo tipo de reconocimiento e interés, al mismo tiempo que invita al espectador al análisis. Simplemente José tiene una fuerte textura poética memorialística que lleva al espectador al momento de la guerra colombiana para luego redirigirlo al sueño por la paz. Por otra parte, los espectadores, receptores de la transmisión de esa posmemoria fuertemente mediada y de un testimonio "por delegación", realizan una recontextualización continua en la que intervienen conexiones afectivas que se activan en la obra de teatro y son tejidas con los recuerdos propios tamizados por la formación cultural y política.

16 Casado Rubio afirma que, al contar sus historias en la escena, su intención es decirle a los espectadores: "Che, ustedes son parte activa de esta historia, no están ahí simplemente mirando y sentados en sus butacas, han de moverse para ver, han de afinar sus oídos para escuchar, han de abrir sus corazones para sentir y dejarse llevar. Propongo un esfuerzo emocional en el espectador" (Casado Rubio, entrevista). 


\section{Afectividad ${ }^{17}$ y biopolítica: resistencia desde la biopotencia}

\begin{abstract}
¿Cuáles son las posibilidades de politizar la desidentificación, esta experiencia de reconocimiento errado, ese incómodo sentido de estar bajo un signo para el cual uno pertenece y no pertenece?
\end{abstract}

(Butler, citada en Athanasiou 377)

Interesa considerar cuál es la relación que la atmósfera afectiva y la respuesta emotiva de nuestros personajes tienen con la política de un modo más específico. Consideremos la diferencia que hace Foucault entre dos aspectos de la biopolítica: por una parte, el biopoder, que es la imposición desde el poder de las normas y restricciones que incluye el todo de la vida en la política y, por otra, la biopotencia, que es la resistencia, desde abajo, que busca la defensa de la vida frente al biopoder que impone la disciplina, la seguridad y la normalización para forzar la homeostasis.

El biopoder y la biopotencia tienen una disimetría ontológica que se explicita en el escenario: en Millones de segundos, en la fisura que resulta de la resistencia de Alan para aceptar la negación de sus derechos que se origina en del statu quo fincado en la tradición y la conveniencia del capitalismo, y en Simplemente José, entre una guerra en busca de sostener un sistema económico (narcotráfico y neoliberalismo) y el impulso deseante de una vida con acceso a los derechos para todos (en primer lugar, la vida misma y, luego, un hogar, una pertenencia, etcétera). En los dos escenarios, el espectador se encuentra frente a dos formas distintas de entender la existencia y de clasificar y valorar la vida, una disimetría ontológica entre la existencia propuesta por el biopoder y aquella buscada por

17 Spinoza, en su Ética, define las "afecciones como los cambios del cuerpo finito mediante los cuales su capacidad de acción es aumentada o disminuida (citado en Lossigio 403). Por un lado, hay factores externos y, por otro, necesidades de nuestra propia naturaleza, que actúan sobre nosotros y nos afectan disminuyendo o incrementando nuestro poder respectivamente. Spinoza distingue entre afectos/pasiones y afectos/acciones. Los primeros son causados por causas externas a nosotros y no conducen a la acción; los segundos nacen de nuestra propia naturaleza, que es la lucha por perseverar en el propio ser y nos convierten en seres activos. Cuando las cosas externas actúan sobre nosotros somos pasivos a ellas y nuestros afectos son pasiones. No estoy de acuerdo en este punto con Spinoza puesto que adhiero a lo propuesto por la corriente del giro afectivo que reconoce también a los llamados afectos negativos su posibilidad de resistencia y de acción, como lo muestran estas dos propuestas teatrales que cuestionan posiciones políticas del statu quo contemporáneas y que activan consciencias y memorias de resistencia. 
la biopotencia. En esta intersección se despliega la estructura dramática en la que el antagonista es el sistema mismo.

La biopotencia - personificada en José y en Alan- se relaciona con la "política", entendida como el resurgimiento y la configuración de eventos de esperanza y la resistencia a los intentos de nombrar, conocer, orientar, clasificar y jerarquizar la vida. La política tiene como característica fundamental el desarrollo de las potencialidades de los sujetos (Ranciere y Virno) y la producción de dinámicas aleatorias que expresen y contengan el pujo de la vida que resista y exceda el intento de orden y control proveniente del biopoder (biopotesta). La biopotencia se expresa en la emergencia de formas sociales y, en nuestro caso se expresa por medio de formas emotivas y teatrales, que actúan en defensa de la vida, descubren y rehúsan el imperativo del biopoder como definitivo.

En la escena, la biopotencia es el motor que moviliza a los personajes para la defensa de la vida y el impulso a resistir, insistir y desarrollar alternativas fuera de la normatividad y de la disciplina del poder. En el caso de José, la potencia excede el mecanismo de control, pero sólo en el nivel teatral-imaginario; en el caso de Alan, la exigencia de una vida plena, expresada en su resistencia, es finalmente sometida al sistema dominante mediante la violencia de género. ${ }^{18}$ Sin embargo, en los dos casos se puede hablar de teatralidades que permean un tono pesimista, situaciones de las que no hay salida: en Simplemente José, el escape es solamente imaginario y, en el caso de Millones de segundos, Alan es asesinado y con él termina la resistencia.

Tanto Alan como José son lo que Butler ha llamado "sujetos precarios", sus vidas no son valoradas y por ello pueden ser desechadas en función de la conservación del sistema; ellos están privados no sólo de bienes sino de visibilidad, audibilidad y capacidad de agencia; el sistema es el principal antagonista de Alan que lucha intentando escapar de "el lugar del no estar", el no lugar del no ser (Butler y Athanasiou, citado en Lossigio 56); en los dos casos, el sistema es el antagonista a nivel de estructura teatral.

Millones de segundos escenifica la expansión de la normatividad. ${ }^{19}$ Reconocer la diversidad de género es poner en jaque la distinción entre "normal" y "anormal" y ello amenaza la necesi-

18 Esto se observa en los colectivos artístico-teatrales que desafían la biopotestas y proponen modos de vida alternativos, como es el caso del Teatro Comunitario argentino. La práctica de la biopotencia/lo político es constitutiva de lo común (Negri, citado en Anderson 36) implica un giro deliberado y abrupto del enfoque de la vida como objetivo último. Es a través de sentimientos corporales, irrupciones, de emoción y afectos colectivos que nuevos modos de vivir pueden aparecer, produciendo un poder expansivo, una partición ontológica que es el poder de la libertad (Negri, citado en Anderson 38).

19 Esta expansión no ocurre solamente en los estados de excepción, un ejemplo es el establecido de hecho con la guerra colombiana que ocurre en el medio de la "democracia". 
dad de mantener los parámetros para la reproducción y mantenimiento del sistema (Anderson 34); denunciar la guerra que se hace con el pretexto de luchar con el narcotráfico, es también ir contra una "normalidad" salvadora establecida desde el poder como inescapable.

En Millones de segundos, desde el biopoder -la justicia y sus dictámenes- el sistema genera condiciones ad hoc para no cumplir la ley de la diversidad de género; a Alan se le niega la operación de transgénero con la justificación de que sufre Asperger. Se ha agregado una condición no establecida por la ley para impedir su cumplimiento y la inclusión de Alan en lo social; tal como nuestro personaje lo señala: "no me vengan con que hay leyes, porque no se cumplen". La escena de Casado Rubio saca de quicio a la supuesta homogeneidad y descubre la pretensión hipócrita legal.

En Simplemente José, la intensificación de la normalización, su expansión y la disciplina han llegado al extremo: la guerra. Esto con el objeto de proteger la vida valorada por el sistema, la defensa de la vida "productiva" y de la necesidad de tomar la tierra para la reproducción del neoliberalismo, aunque en el intento se termine con aquellas vidas "prescindibles", vidas devaluadas cuya desaparición se justifica. José, nuestro personaje, es una de ellas, ha sido desplazado de su lugar de vida. La guerra colombiana como una forma extrema de la disciplina y la normalización capitalista neoliberal es aquello a lo que José resiste sin otra arma que sus emociones, la memoria y su imaginación poética que surgen como respuesta al clima afectivo generado por la situación. Mientras tanto:

las fuerzas paramilitares siguen avanzando en un proceso de acumulación de capital a través del desplazamiento forzado de comunidades en zonas de importancia económica...[cuando] Una gran parte de los ciudadanos de Colombia siguen abandonando sus tierras de las que son desplazados por la fuerza... satisfaciendo el apetito voraz de las corporaciones multinacionales extranjeras (principalmente de Estados Unidos) por el territorio colombiano, a la vez que se arraiga el programa económico neoliberal en la sociedad colombiana (Maher 96).

José y Alan no han corporizado los controles que dominan las acciones a través de las emociones y los sentimientos de éxito o de culpa, sus cuerpos y sus mentes no han sido automatizadas, no son obedientes ni funcionales al sistema. Esto marca la relación de la afectividad y la respuesta emocional de la escena a la imposición política desde el biopoder. Sus cuerpos escapan a la disciplina que busca consolidar el control marcando normas de conducta que limitan lo que el cuerpo puede o no puede hacer (Foucault 46-57). Los dos protagonistas luchan por existir, alejándose de la amenaza de la muerte física, en el caso de José, y de la muerte social, en el caso de Alan, y resisten las circunstancias externas que ponen en peligro su supervivencia en plenitud. 
Mientras el sueño de Alan es bailar, José rechaza la violencia generada por la guerra y quiere seguir siendo el campesino que viva en su entorno al que ama; sólo desea conservar su modo de vida:

algún día voy a volver a mi casa blanca de todos mis sueños, yo quiero volver a correr por los potreros y mirar las nubes del cielo con mi amigo Tobías, quiero sentir la risa y el olor de las mañanas, yo... algún día encontraré mi camino... quiero volver a comer mamoncillos y saltar en las camas... tomar chocolate caliente, sentir el frío de la noche... quiero ver las estrellas, quiero volver a mi casa....

Alan, en cambio, persigue conseguir el cuerpo que le permita tener la identidad que ha elegido, afirmar su capacidad de decisión y el conocimiento de su propio cuerpo: salir del cuerpo no deseado. La evolución de la acción, en los dos productos teatrales, se expresa en la reacción emotiva de los personajes frete a la atmósfera afectiva de la guerra y de la discriminación de género.

\section{Conclusión}

Cuando la actividad estética o literaria crea sus formas, éstas no son una repetición de aquello que ya existe como una memoria o un evento conocido para el sujeto o la cultura. Se trata de ocasiones para un encuentro potencialmente transformador marcado por la potencialidad de la estética para tocar, identificarse con y para formular el trauma como una huella, como trazado.

(Pollock 7)

La emoción y el sentimiento que José y Alan expresan en el escenario surgen del conocimiento de sus respectivas situaciones. Las emociones, que emergen frente a la atmósfera afectiva de la guerra y la discriminación, exceden los mecanismos biopolíticos de control para intentar encontrar otro modo de vida por afuera de la "norma". Es en esta resistencia donde aparece la "política de los afectos" que se sitúa en la dinámica dialéctica de la lucha de estos dos personajes entre aquello que los afecta enraizado en el biopoder y sus sueños o acciones imaginarias, que intentan desenmascarar el origen de esa afectación y revertirla mediante la acción que surge de la resistencia de la vida: la biopotencia. 
INVESTIGACIÓNTEATRAL

Revista de artes escénicas y performatividad

Vol. 11, Núm. 18

octubre 2020-marzo 2021
Afectividad, política y conocimiento

Lola Proaño Gómez

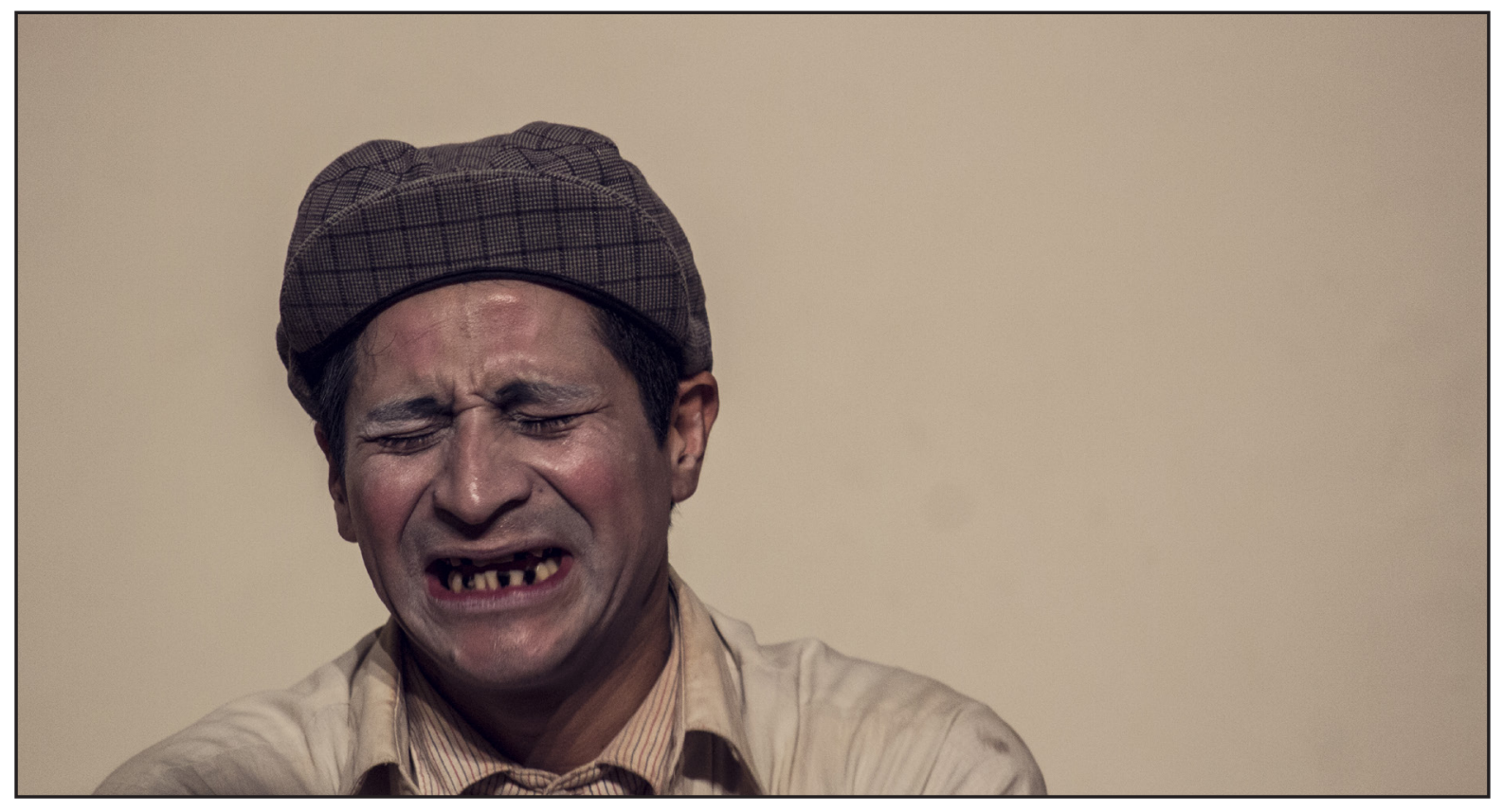

Simplemente José. X2 Teatro, Manizales, Colombia. VII Muestra de Teatro Alternativo de Pereira, 27 de julio de 2015. Fotografía de Andrés Felipe Rivera.

Tanto José como Alan tienen una posición antagónica respecto del sistema neoliberal cuando valoran justamente aquello que este sistema, que los afecta, desprecia: conocerse a sí mismo, disfrutar la naturaleza, traer a la memoria los tiempos vividos, buscar el reconocimiento del derecho a la diferencia que, en el caso de Millones de segundos, se delinea en la negación de la necesaria simetría entre biología e identidad sexual; disimetría que va contra las necesidades del sistema que necesita cuerpos reproductores de la fuerza de trabajo y subjetividades aptas para el modelo neoliberal. Los dos personajes resisten las técnicas de la afectividad del neoliberalismo (publicidad, manejo del deseo para obtener el consumo y entrega del cuerpo como herramienta para la producción y la reproducción) mediante el conocimiento que obtienen en sus emociones convertidas en acción en el escenario. En Simplemente José, la afectividad es el modo de proponer una recepción táctil, auditiva y visual del pasado. El escenario de Largo León, al igual que la poesía, logra expresar de manera inefable ese extra que escapa a la palabra y al razonamiento fríamente lógico de la ganancia.

Los afectos constituyen una lógica singular capaz de dar cuenta de los lazos sociales, de influir en la capacidad del cuerpo para la acción. El sufrimiento (sentimiento negativo), como hemos visto en Simplemente José y en Millones de segundos, no implica pasividad: estos dos sujetos no se ensimisman; en el primer caso, José crea un espacio imaginativo de 
retorno a un pasado mejor, correspondiente al tiempo anterior a la guerra, para mostrar el sinsentido de la misma; en el segundo caso, Alan discute, razona y esgrime sus derechos e intenta pasar a la acción política fuera de su espacio.

En las dos instancias tenemos cuerpos involucrados en fuertes emociones, cuerpos que, impactados por la atmósfera afectiva, producen acciones y pensamientos que hablan de la biopotencia que se enfrenta con el poder. Los afectos aparecen con una cualidad performativa que supera la del lenguaje verbal (actos del habla de Austin) puesto que involucra el cuerpo y todos los lenguajes teatrales.

Los dos escenarios descritos son un buen ejemplo del carácter cognitivo de las emociones y de su papel central en los planteos políticos (Nussbaum, citado en Macón 14). Simplemente José y Millones de segundos dan cuenta de experiencias tomadas de la realidad, situadas en tiempo y espacio; ellos -señuelos nuestros en situaciones similares- tienen la capacidad, desde la contingencia, para denunciar y establecer demandas expresadas afectivamente y exhibir el doble estándar del sistema político que resguarda unas vidas y precariza otras hasta la muerte.

Simplemente José propone, desde la marginalidad, una masculinidad opuesta a la que está sostenida tradicionalmente en el ocultamiento de los afectos que, en este caso expresados poética y teatralmente, son funcionales en la propuesta para la denuncia de la injusticia de la guerra y para la expresión del deseo de la paz en Colombia. Millones de segundos también va a contracorriente oponiéndose a los patrones educativos, medicinales, de estructura familiar y de género que, si bien formalmente pueden parecer resueltos, no lo están en la atmósfera afectiva general de la Argentina en el presente.

Desde lo afectivo, es posible leer cómo las dos obras exhiben "nuevos órdenes de asociación afectiva" (Hirsch, citado en Taccetta, "Arte, afectos y política" 307) que adquieren sentido articulados con los respectivos contextos. Parece entonces posible afirmar que el teatro es el espacio adecuado para la asociación de la afectividad con la política mediante lenguajes que desbordan los significantes lingüísticos; la escena logra generar la "comprensión afectiva" que va más allá de la interpretación y de la explicación mediante un proceso de afectación que es como "una coloración de todo nuestro ser, una apertura hacia algo" (ibídem). De este modo, la experiencia mediada por la estética abre un camino al conocimiento comprehensivo mediante la creación de un espacio tiempo originario para lo que Pollock llama "ondas afectivas alrededor de lo no-experienciado" (citato en Taccetta, "Poiesis y postafectos" 63-66), ondas que llegan a la sensibilidad y a la mente del espectador. De este modo, tanto José como Alan, nuestros dos protagonistas, dan un testimonio estético que transforma traumas o experiencias individuales en pos-memoria colectiva. 


\section{Fuentes consultadas}

Abramowski, Ana y Santiago Canevaro, compiladores. Pensar los afectos. Aproximaciones desde las ciencias sociales y las humanidades. Buenos Aires: Universidad Nacional General Sarmiento, 2017.

Abramowski, Ana. "La vocación como categoría afectiva fundante de docencia como profesión". Pretérito indefinido. Afectos y emociones en la aproximaciones al pasado, editado por Cecilia Macón y Gabriela Solana. Buenos Aires: Título, 2015.

Agamben, Giorgio. Lo que queda de Auschwitz: el archivo y el testigo, homo sacer III. Valencia: Pre-Textos, 2000.

Anderson, Ben. "Affect and Biopower: Towards a politics of life". Transactions, Institute of British Geographers, 12 de abril de 2011, onlinelibrary.wiley.com/doi/abs/10.1111/ j.1475-5661.2011.00441.x, consultado el 1 de junio de 2018.

Athanasiou, Athena. ¿QQuién es aquel nombre? Sujetos de género y resistencia queer o el deseo de disputa". Pretérito indefinido. Afectos y emociones en la aproximaciones al pasado, editado por Cecilia Macón y Gabriela Solana. Buenos Aires: Título, 2015.

Buttler, Judith y Athena Athanasiou. Dispossession: The Performative in the Political. Cambridge: Polity, 2013.

Casado Rubio, Diego. Entrevista electrónica personal. 19 de junio de 2018.

Depetris Chauvin, Irene. “Texturas del pasado, performances del presente”. Pretérito indefinido. Afectos y emociones en las aproximaciones al pasado, editado por Cecilia Macón y Gabriela Solana. Buenos Aires: Título, 2015, pp. 113-135.

Foucault, Michel. "The Confession of the Flesh". Power/Knowledge: selected interviews and other writings 1972-1977. Brighton: Harvester Press, 1980, pp. 194-228.

Leys, Ruth. "The Turn to Affect: A Critique”. Critical Inquiry, vol. 37, núm. 3, 2011, pp. 434-472.

Losiggio, Daniela. "La política desde el affective turn: el rescate de las pasiones". Pensar los afectos. Aproximaciones desde las ciencias sociales y las humanidades. Buenos Aires: Universidad Nacional General Sarmiento, 2017.

Macón, Cecilia y Mariela Solana, editoras. Pretérito indefinido. Afectos y emociones en las aproximaciones al pasado. Buenos Aires: Título, 2015.

Maher, David y Andrew Thomson. “The terror that underpins the 'peace': the political economy of Colombia's paramilitary demobilisation process". Critical Studies on Terrorism, vol. 4, núm.1, 2011, pp. 95-113.

Nussbaum, Martha. Political Emotions. Why Love Matters for Justice. Londres: Harvard University Press, 2013. 
Pollock, Griselda. After-Affects/After-Images. Trauma and Aesthetic Transformation in the Virtual Feminist Museum. Manchester y Nueva York: Manchester University Press, 2013.

Proaño Gómez, Lola. Poética, política y ruptura. La "Revolución Argentina"(1966-1973): experimento frustrado de imposición liberal y "normalización de la economía. Argus-a, www.argus-a.com.ar/ebook/739-poetica-politica-y-ruptura-la-revolucion-argentina-1966-73-experimento-frustrado-de-imposicion-liberal-y-normalizacion-de-laeconomia.html, consultado el 8 de octubre de 2020.

Solana, Mariela. "El tiempo de las locas. Temporalidad, emociones y sexualidades disidentes". Pensar los afectos. Aproximaciones desde las ciencias sociales y las humanidades. Buenos Aires: Universidad Nacional General Sarmiento, 2017.

Taccetta, Natalia. "Poiesis y postafectos. Ansiedades artísticas en la posdictadura argentina". Pensar los afectos. Aproximaciones desde las ciencias sociales y las humanidades, editado por Cecilia Macón y Gabriela Solana. Buenos Aires: Universidad Nacional General Sarmiento, 2017.

Taccetta, Natalia. "Arte, afectos y política. O de cómo armar un archivo". Pretérito indefinido. Afectos y emociones en las aproximaciones al pasado, editado por Cecilia Macón y Gabriela Solana. Buenos Aires: Título, 2015.

Vidal, Hernán. Crítica literaria como defensa de los derechos humanos: cuestión teórica. Newark: Juan de la Cuesta, 1994.

Virno, Paolo. A grammar of the Multitude. For an Analysis of Contemporary Forms of Life. Nueva York: Semiotext(e), 2004.

Williams, Raymond. "Estructura del sentir". Marxismo y Literatura. Barcelona: Península, 1977. 